\title{
Case series - retrorectal cystic hamartomas
}

\begin{abstract}
The retrorectal (presacral) space is a not very common site for neoplastic tumors. Retrorectal cystic hamartomas (RCHs) or tailgut cysts (TGCs) are rare congenital lesions, typically presented as presacral masses. Due to its potential of infection, fistulas and malignancy, early diagnosis and surgical treatment are mandatory. In this article, it is described the clinical, radiological and pathological features of five cases.
\end{abstract}

Keywords: tailgut cysts, retrorectal cystic hamartomas, presacral tumors, kraske procedure, posterior approach
Volume 3 Issue 4 - 2017

\author{
Guilherme Zupo Teixeira, Andressa \\ Marmiroli Garisto, Regina Greilberger \\ Ribeiro, Antônio José Tibúrcio Alves, Luciane \\ Hiane de Oliveira, Sérgio Oliva Banci, \\ Joaquim Simões Neto, Odorino Hideyoshi \\ Kagohara, Jose Alfredo Reis Junior, José \\ Alfredo Reis Neto \\ Clínica Reis Neto, Campinas, Brazil
}

Correspondence: Guilherme Zupo Teixeira, Clínica Reis Neto, R. Gen. Osório, 2273-Cambuí, Campinas-SP, Brazil,Tel +55193252561।,Email guizupo@hotmail.com,

antonio_xxxv@yahoo.com.br
Abbreviations: TGCs, tailgut cysts; RCHs, retrorectal cystic hamartomas; US, ultrasound; CT, computed tomography; MRI, magnetic resonance imaging

\section{Introduction}

The retrorectal (presacral) space is a not very common site for neoplastic tumors. It can include primary tumors of neurogenic, osteogenic, and congenital origin; in addition to metastatic and inflammatory processes. Congenital lesions include chordomas (remnants of notochord), teratomas, anterior sacral meningoceles, and developmental cysts (dermoid, epidermoid, enteric duplication, and TGCs). TGCs, or RCHs, are benign uncommon lesions that may appear in this area. They are thought to arise from vestiges of the embryonic hindgut. Despite its congenital origin, may be diagnosed in infants or adults. It's usually presented in a multicystic pattern. With incidence between 1:40000 and 1:63000, it preferably affects middleaged women. ${ }^{1,2}$ The potential of malignancy in retrorectal cystic hamartomas is extremely rare..$^{3,4}$

\section{Materials and methods}

From 2015-2017, 3 cases of retrorectal cystic hamartomas were operated by Clínica Reis Neto staff (Campinas, SP, Brazil), on female patients between 27 e 57years old, by posterior approach (Kraske procedure), after MRI. Diagnosis was histologically confirmed.

\section{Case \#I presentation}

44year-old female, presented with continuous rectal discharge for the past 3years, since surgical drainage of extrinsic bulge in rectum. There was no history of abdominal pain, bleeding per rectum, urinary complaints or abnormal menstrual cycle. Digital rectum examination showed a extrinsic, tender, retrorectal mass compressing the rectum, with small amount of thick brownish discharge.

\section{Case \#2 presentation}

57year-old female, reporting to the urgency service with sepsis from infected retrorectal cyst, with previous surgical drainage of "infected pilonidal cyst". On physical examination, presented purulent discharge from left gluteal region. On per rectal examination, there was a mass bulging from the posterior rectal wall, tender, moldable, with smooth mobile rectal mucosa over it. Surgery demonstrated coccyx osteomyelitis, needing coccygectomy.

\section{Case \#3 presentation}

27year-old female, complaining about tenesmus and proctalgy during evacuations. There were no relevant antecedents. She denied abdominal pain, urinary alterations, abnormal menstrual cycle, bleeding per rectum. Physical examination showed a firm, non-tender, tumor bulging from the posterior rectal wall, with regular surface and smooth mobile rectal mucosa over it.

\section{Case \#4 presentation}

A female patient was diagnosed at age 13 with Currarino Syndrome after clinical suspicion of a rectal tumor due to recurrent abscess in the sacral region and chronic constipation. Subsidiary imaging studies showed a presacral tumor with cystic features in the retrorectal region compressing the intestinal lumen. The patient underwent surgical intervention incising the dermoid cyst that recurred two months after drying up again. Later, another surgery was necessary after spontaneous secretion drainage in the sacral region and curettage revealed granulation tissue. The fistula was then obliterated with fibrin glue. Up to three months postoperative the patient had no signs of recurrence. After a five year follow up the patient returned with retrorectal tumor and drainage of pus in the broad path of the sacral region. It was opted for surgery with posterior approach, resection of the coccyx and the last three sacral vertebrae and resection of the rectal wall with preservation of pelvic floor plans. Pathologic examination showed dermoid cyst without signs of malignancy. The patient has a good outcome without signs of recurrence after four months of postoperative.

\section{Case \#5 Presentation}

40-year-old female, asymptomatic, without relevant antecedents. Cystic mass found on MRI, during uterine myoma investigation. On 
digital rectal examination, tender, firm, well-defined, extrinsic mass on the posterior wall, with smooth mobile rectal mucosa over it.

\section{Discussion}

The retrorectal space is limited anteriorly by the rectum and posteriorly by the sacrum. The superior border is formed by the peritoneal reflection, and the inferior, by levator ani and coccygeus muscles. In this region, different neoplastic and non-neoplastic conditions can occur. ${ }^{5-9}$ Teratomas are mostly diagnosed in children. In adults, chordoma and developmental cysts are more frequent. ${ }^{5,9,10}$

Nearly half the patients are asymptomatic; symptoms result from mass effect or from secondary infection. Investigations include imaging examination (US, endosonography, endoscopy, CT or MRI). The cyst diameter may range from 2 to $12 \mathrm{~cm}$. It may be unilocular or multilocular. Although not requested in the presented cases, ultrasound and CT can be done in the initial investigation. Transrectal US may show a multilocular, retrorectal cystic mass. Internal echoes may be found within the cyst due to the multi-cystic nature of the mass and the presence of gelatinous material or inflammatory debris within the cyst. CT findings can often see a discrete, well-marginated, presacral mass with water or soft-tissue density, depending on the contents of the cyst. Calcifications may be seen in the cyst wall. When the mass is large, the rectum is displaced by the mass. If concurrent infection or malignant transformation occurs, CT may reveal loss of discrete margins and involvement of contiguous structures. In uncomplicated cysts (without infection, inflammation, or malignant change), MRI features (Figure 1) are low signal in T1 and high signal in T2. In complicated cysts, $\mathrm{T} 1$ shows high signal components may occur due to the presence of mucinous material, high protein content, or associated intracystic hemorrhage, and T2 shows low signal components may occur due to the presence of hemorrhage or associated keratin. ${ }^{11}$
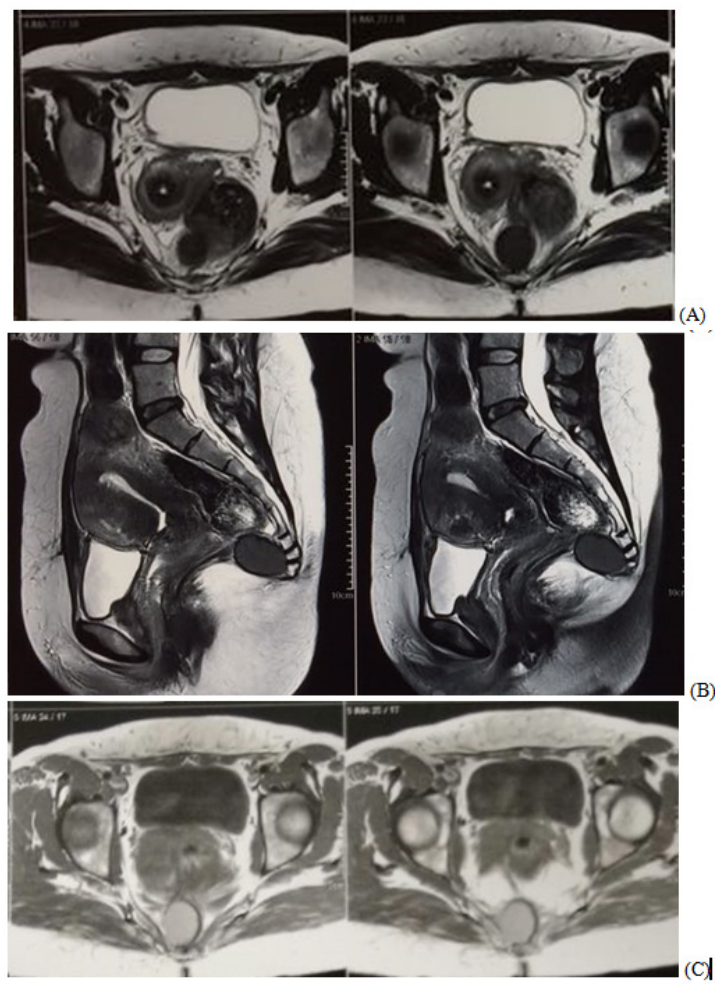

Figure I MRI shows a retrorectal cystic mass compatible with RCH.T2 (A and $B$ ) and $T I(C)$.
Different epithelial linings may be found: stratified squamous, cuboidal, transitional, stratified columnar, mucinous or ciliated columnar cells. Interrupted bundles of smooth muscle are present., ${ }^{4,12,13}$ Differential diagnosis of $\mathrm{RCH}$ are epidermoid cysts, dermoid cysts, enteric or rectal duplication cysts, and cystic teratomas. ${ }^{12-14}$ The pathologic diagnosis based on biopsy is difficult, because its specimens often contain only inflamed fibrous tissue without epithelia or only 1 type of epithelium, usually squamous. Malignant change as a rare complication has been described occasionally. ${ }^{1,3,12}$

In conclusion, RCHs are rare conditions, which diagnosis is often delayed, partly due to unfamiliarity with this entity and also because of its non-specific clinical manifestations. Due to its potential of infection, fistulas and malignancy, early surgical excision is indicated when suspected (Figure 2). Prognosis is favorable if adequate surgical margins (Figure 3).
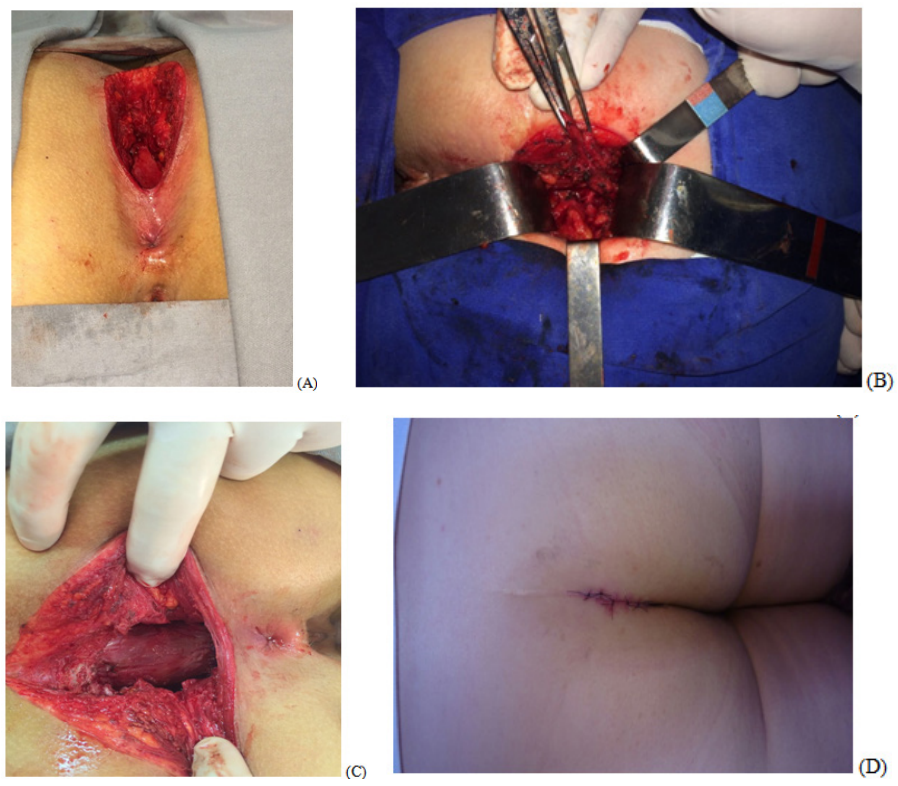

Figure 2 Posterior access/Kraske procedure; overview (A), intraoperative dissection (B), posterior rectal wall (C) and postoperative aspect (D).
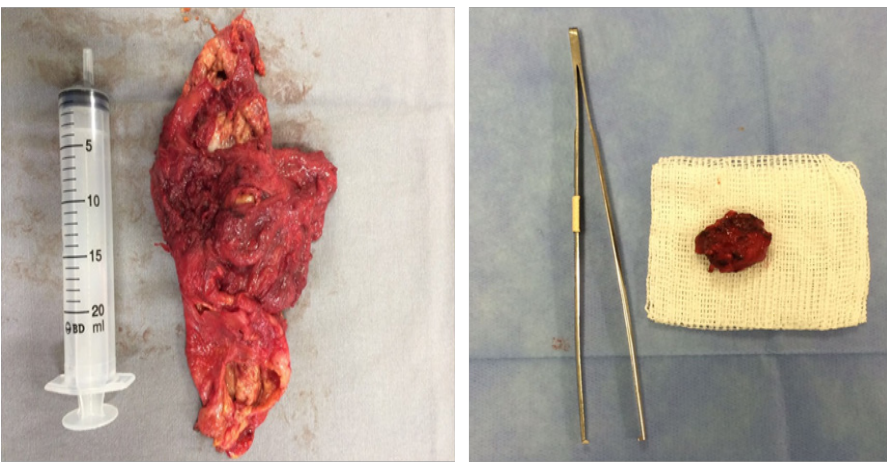

Figure 3 Surgical resection specimens.

\section{Acknowledgements}

None.

\section{Conflict of interest}

Author declares that there is no conflict of interest. 


\section{References}

1. Tampi C, Lotwala V, Lakdawala M, et al. Retrorectal cyst hamartoma (tailgut cyst) with malignant transformation. Gynecol Oncol. 2007;105(1):266-268.

2. Sung MT, Ko SF, Niu CK, et al. Perirenal Tailgut Cyst (Cystic Hamartoma). Journal of Pediatric Surgery. 2003;38(9):1404-1406.

3. Slim Jarboui, Hichem Jarraya, Mohamed Ben Mihoub, et al. Retrorectal cystic hamartoma associated with malignant disease. Can J Surg 2008;51(6):E115-E116.

4. Anil R Prasad, Mahul B Amin, Todd L Randolph, et al. Retrorectal Cystic Hamartoma. Archives of Pathology \& Laboratory Medicine. 124(5):725-729.

5. Jao SW, Beart RW, Spencer RJ, et al. Retro rectal tumors: Mayo Clinic experience, 1960-1979. Dis Colon Rectum. 1985;28(9):644-652.

6. Wang JY, Hsu CH, Changchien CR, et al. Presacral tumor: a review of forty-five cases. Am Surg. 1995;61(4):310-315.

7. Hannon J, Subramony C, Scott-Conner CE. Benign retrorectal tumors in adults: the choice of operative approach. Am Surg. 1994;60(4):267-272.
8. Freier DT, Stanley JC, Thompson NW. Retrorectal tumors in adults. Surg Gynecol Obstet. 1971;132(4):681-686.

9. Uhlig BE, Johnson RL. Presacral tumors and cysts in adults. Dis Colon Rectum. 1975;18(7):581-596.

10. Hjermstad BM, Helwig EB. Tailgut cysts: report of 53 cases. Am J Clin Pathol. 1988;89(2):139-147.

11. Kim MJ, Kim WH, Kim NK, et al. Tailgut cyst: multilocular cystic appearance on MRI. J Comput Assist Tomogr. 1997;21(5):731-732.

12. Prasad AR, Amin MB, Ranolph TL, et al. Retrorectal cystic hamartoma: report of 5 cases with malignancy arising in 2. Arch Pathol Lab Med. 2000;124(5):725-729.

13. Jang SH, Jang KS, Song YS, et al. Unusual prerectal location of a tailgut cyst: a case report. World J Gastroenterol. 2007;12(31):5081-5083.

14. Mills SE, Walker AN, Stallings RG, et al. Retrorectal cystic hamartoma: report of three cases, including one with a perirenal component. Arch Pathol Lab Med. 1984;108(9):737-740. 